\title{
ESTRATEGIAS DE RESISTENCIA INDÍGENA FRENTE AL DESARROLLO MINERO. LA COMUNIDAD DE LIKANTATAY ANTE UN POSIBLE TRASLADO FORZOSO
}

Anita Carrasco ${ }^{1}$ y Eduardo Fernández ${ }^{1}$

\begin{abstract}
Este artículo revisa el complejo panorama que enfrenta la comunidad indígena atacameña de Likantatay ante las consecuencias de un proyecto de desarrollo minero que implican el traslado forzoso de dicha comunidad si este proyecto se concreta. Se analizan las estrategias de resistencia indígena que presenta y/o puede presentar la comunidad así como los discursos y estrategias ideológicas elaborados por la corporación minera para desarrollar los intereses del capital. El análisis se enmarca dentro de una discusión teórica en la que se identifican dos sistemas éticos subyacentes y en confrontación: la ética (utilitarista) de la corporación vs. la ética (deontológica) de la comunidad.

Palabras claves: Atacama - ideología - comunidad indígena - minería sistemas éticos - desarrollo - desplazamientos - migración.
\end{abstract}

Abstract

This article reviews the complex scenario confronted by the indigenous community of Likantatay in the face of the consequences of a mining development project and the potential forced resettlement that this project would imply for the community. The article provides an analysis of the strategies of indigenous resistance that are present or potentially present among the community and the discourses and ideological strategies elaborated by the mining corporation to advance the interests of capital. The latter analysis is framed in a theoretical discussion which identifies two underlying ethical systems which confront each other: the corporation's ethics (utilitarian) vs. the community's ethics (deontological).

Key words: Atacama - ideology - indigenous community - mining ethical systems - development - displacements - migration.

Recibido: octubre de 2008. Aceptado: agosto de 2009.

\footnotetext{
1 School of Anthropology, The University of Arizona, 1009 E. South Campus Drive, Tucson, Arizona 85721-0030 ESTADOS UNIDOS. Email:

anitac@email.arizona.edu; Email:eduardof99@yahoo.com
}

En la actualidad existe cierta tendencia entre promotores, analistas e, inclusive, críticos del desarrollo en dar por sentado el hecho de que no existe alternativa alguna al modelo de desarrollo neoliberal que sea viable o proes cómo hacer de ese modelo de desarrollo algo sustentable y más humano. Este artículo discutirá la puesta en marcha de un proyecto de explotación minera y el potencial traslado forzoso que enfrentaría la comunidad indígena atacameña de Likantatay de ejecutarse dicho proyecto. Likantatay se ubica en el sector poniente de la ciudad de Calama en el norte de Chile (Figura 1) y, para fortuna de algunos y desgracia de otros, sobre un depósito de cobre perteneciente a la empresa minera estatal CODELCO (Corporación Nacional del Cobre).

Aquí se analizará la existencia y difusión por parte de CODELCO de un subyacente discurso ético de corte utilitarista, que a grandes rasgos, define la ejecución de una acción determinada como moralmente aceptable cuando el bien total resultante es mayor si se compara al total de los aspectos negativos que la misma acción genera. Desde el punto de vista de CODELCO, el acto moralmente aceptable, o si se quiere, el "bien", es que el cobre sea explotado. Para sugerir que ese acto genera un bien mayor se arguye con base en criterios numéricos monetarios y poblacionales, que la explotación del mineral beneficia el ingreso de divisas de todo el país y de esta manera, a la nación chilena en general. En contraste, en este caso particular, el "mal" generado por la explotación de cobre sería la desaparición y la desarticulación de la comunidad Likantatay. metedora. La única salvedad que pareciera quedar en pie 


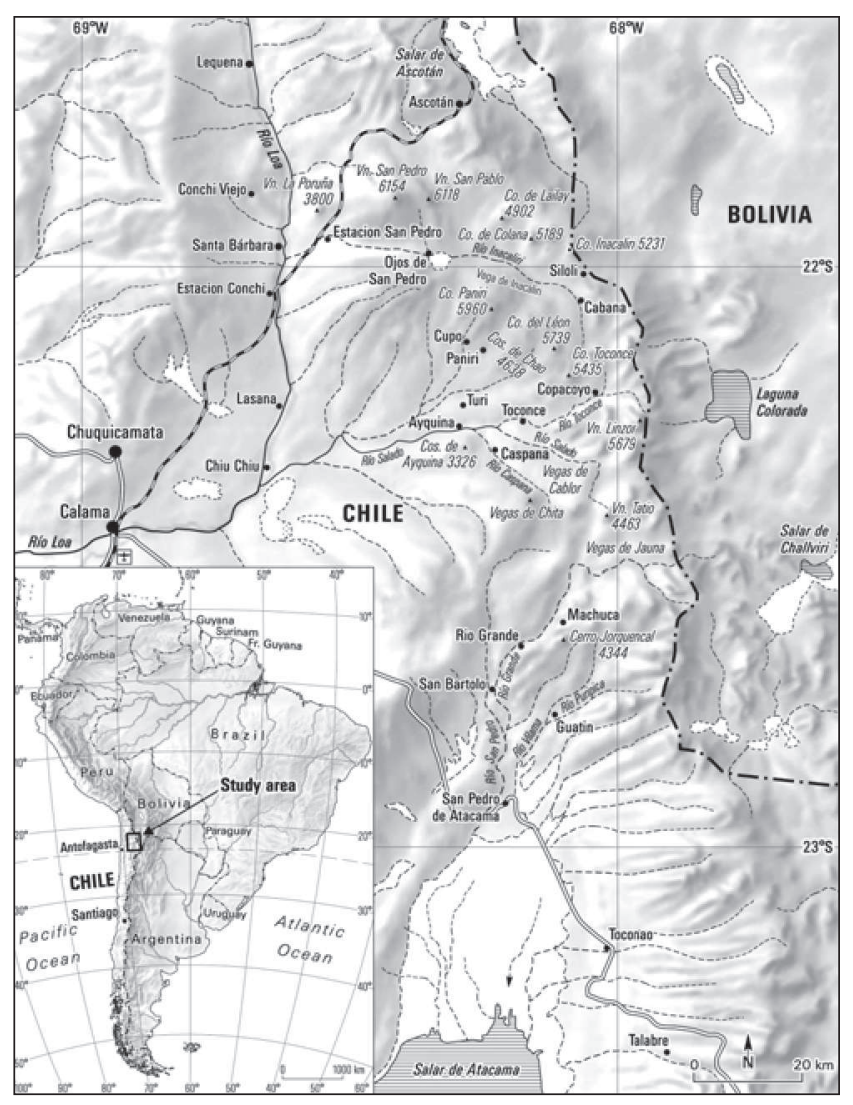

Figura 1. Mapa del área de estudio por Fernando Maldonado y AndreasBrodbeck en: Castro y Aldunate (2003: 74).

Las justificaciones ideológicas basadas en una ética utilitarista generalmente tienen el efecto de situar en desventaja la agencia que pudieran tener comunidades como Likantatay al momento de confrontar la puesta en marcha de proyectos de desarrollo en sus tierras, en la medida que sus intereses son los de una minoría. Es sabido que en los estados modernos los gobiernos toman decisiones respecto al desarrollo de proyectos de inversión que necesariamente implican el perjuicio de un grupo determinado de personas. En la mayoría de los casos, estas personas se ven obligadas a hacer un "sacrificio" en favor de algo que el Estado sostiene beneficiará a todo el país en el largo plazo. Ejemplos de lo anterior abundan en Chile, especialmente en los sectores energéticos y mineros, con la construcción de centrales hidroeléctricas y la explotación de yacimientos de cobre y otros minerales. Un ejemplo reciente y emblemático lo constituye el proyecto aurífero Pascualama de la minera canadiense Barrick Gold en el valle del Huasco. Dicho pro- yecto ha generado un fuerte conflicto socioambiental entre los distintos actores y grupos de interés involucrados (p.e., asalariados rurales, empresarios agroindustriales, asalariados mineros, comunidad religiosa, grupos ambientalistas, y la comunidad mayor, entre otros):

"Este proyecto minero para muchos representa la única salida de desarrollo económico para la comuna de Alto del Carmen e incluso para la región, pero para otros significa una amenaza para su existencia simbólica y material. Esto último dado que la posibilidad de contaminación de las aguas o 'muerte del valle' por falta de aguas y el arribo de una multiplicidad de afuerinos a la comuna y al valle del Huasco, modificarían inevitablemente las prácticas culturales de sus habitantes" (Bourguignat y Ramírez 2006: 98).

Como bien lo ejemplifica el caso de Pascualama, al igual que el de Likantatay, los proyectos de desarrollopaís presentan escenarios complejos de evaluar, dado 


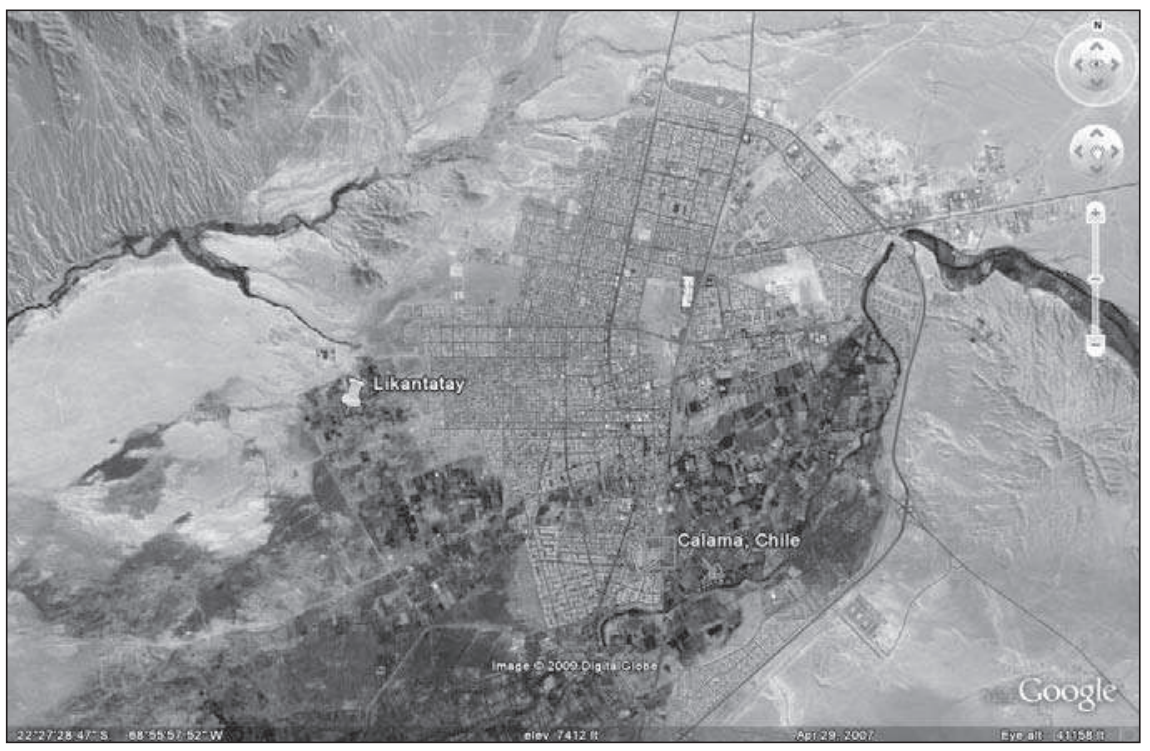

Figura 2. Fotografía digital de la ciudad de Calama tomada de GoogleEarth. En ella se indica la ubicación de la comunidad de Likantatay.

que dividen a las comunidades entre grupos opositores y grupos proclives a dichos proyectos. A pesar de la desventaja en que se encuentran diversos grupos minoritarios en esos casos, este artículo no pretende situar a la comunidad de Likantatay en el tradicional rol de "víctimas", tan comúnmente otorgado a las minorías étnicas por parte de la antropología y otras ciencias sociales. Por el contrario, se quiere señalar también que así como la minería genera un sinnúmero de impactos sobre ellas, éstas también pueden impactar a la minería. ${ }^{2}$ Teniendo en cuenta lo anterior, pretendemos, por un lado, identificar el discurso valórico elaborado por la comunidad indígena para defender sus intereses y, por otro, contrastarlo con el discurso presentado por la empresa minera para avanzar en el logro de sus objetivos. En otras palabras, se dará respuesta general a dos interrogantes: ¿Cuáles son las $\operatorname{armas}^{3}$ que tiene la comunidad indígena para defender

\footnotetext{
2 Sin ir más lejos, el principal grupo opositor al proyecto Pascualama llamado "Comité de Defensa del Valle" generó grandes obstáculos a la minera Barrick Gold, especialmente gracias a su alianza con la Iglesia católica y grupos ambientalistas de fama mundial como Greenpeace.

3 Cuando usamos la palabra "armas" estamos pensando en la discusión teórica elaborada por Scott (1990), la cual se basa en el supuesto de que los "pobres" cantan una canción en presencia de los
}

sus intereses? vs. ¿Cuáles son las armas que tiene la empresa minera para hacer valer sus beneficios? En la identificación de los discursos de la empresa minera y de la comunidad indígena se mostrará cómo tanto unos como otros hacen ingentes intentos por hacer valer su versión ideológica de la "verdad" a la hora de defender sus intereses particulares.

\section{* ORIgen y Formación de la comunidad INDÍGENA DE LIKANTATAY}

Para hablar de Likantatay es necesario revisar brevemente las principales causas que condujeron a que una gran masa de indígenas atacameños de los pueblos del interior de la cuenca del Loa en el norte de Chile se viera compelida a emigrar a centros urbanos como Calama y Chuquicamata (Figura 2). De acuerdo a Sanhueza y Gun-

\footnotetext{
"ricos" y otra canción cuando están entre los pobres. Los ricos también tienen un discurso frente a los pobres y otro para referirse a los asuntos internos entre ricos. Este supuesto llevó al autor a definir las "formas ocultas" (hidden transcripts), que serían las armas de los débiles y entre las cuales lista: estrategias de encubrimiento como el anonimato, los chismes en contra de los poderosos, y el uso de eufemismos. Entre las formas más elaboradas de encubrimiento de críticas al poder señala la cultura oral, cuentos del folklore local y ritos de inversión de roles como en carnavales y fiestas.
} 
dermann (2007) las faenas mineras e industriales de la zona del Loa absorbieron desde los inicios de su período de auge una cantidad importante de mano de obra indígena. La ciudad de Calama en la última década del siglo XIX estaba iniciando un rápido proceso de crecimiento económico y demográfico. Específicamente, las comunidades del pie de la cordillera andina: "habían comenzado un proceso migratorio y un visible asalariamiento hacia la minería, estableciéndose temporal, estacional o definitivamente en los centros mineros y en los alrededores de Calama" (Sanhueza y Gundermann 2007: 132). La expansión de la minería y sus requerimientos de tecnología e infraestructura y comunicaciones se hicieron cada vez más demandantes a medida que avanzaba el siglo XX. Dicha expansión minera fue desplazando las bases agrarias que habían sustentado a las economías atacameñas, y la oferta campesina local fue insuficiente para los requisitos de la expansión minera en la región. De esta manera, el paisaje regional se vio modificado: "La creciente demanda de trabajo minero asalariado sienta las bases para una nueva realidad con vigencia hasta el presente: integración y dependencia indígena del mercado de fuerza de trabajo minero y progresivo asentamiento urbano en Chuquicamata y Calama" (Sanhueza y Gundermann 2007: 134).

Según testimonios de los indígenas de la comunidad de Likantatay las causas de sus migración son de diversa indole. Destacan la falta de oportunidades laborales y la imposibilidad de darles educación a sus hijos en el poblado de origen. Sin embargo, la principal razón que perciben que los obligó a emigrar, fue que el agua para regar sus campos se volvió escasa e insuficiente para sostener las prácticas agrícolas de todas las familias que habitaban cada pueblo. Por ejemplo, el pueblo de Cupo que alguna vez sostuvo a 60 familias regantes, hoy solamente sostiene a seis familias, lo que significó el éxodo de 90\% de la población. Algunos atribuyen la disminución del recurso hídrico a la voracidad de las empresas mineras en la explotación de acuíferos, otros a la falta de lluvias, y la mayoría a una combinación de ambos factores. ${ }^{4}$

4 Las imágenes satelitales de la región de Antofagasta muestran claramente como el desierto de Atacama está marcado por las múltiples tuberías que lo atraviesan y son testimonio irrefutable del volumen de agua extraído para el funcionamiento de la industria minera y las ciudades asociadas a dicha actividad. Un estudio de las causas de la emigración rural-urbana realizado por Bähr en la década de los 80 , señalaba que: "el consumo de agua de seguro
Así, la gente comenzó a abandonar sus pueblos de origen en búsqueda de nuevas oportunidades, lo que a la vez condujo a un mayor deterioro de los campos agrícolas en esos pueblos. De acuerdo a Núñez (1991:259), los atacameños se vieron enfrentados a la siguiente encrucijada: quedarse en sus pueblos luchando por seguir trabajando terrenos agrícolas con poca agua y escasas manos; o migrar a la ciudad y convertirse en trabajadores asalariados cuando se diera la oportunidad. La gran mayoría se vio obligada a tomar la segunda opción y migrar masivamente hacia los centros urbanos de la región, principalmente a Calama. Esta migración trajo como consecuencia directa para quienes iban llegando a las ciudades, la inevitable pérdida de intensidad del estilo de vida campesino propio de los pueblos del interior. En las ciudades, los inmigrantes atacameños buscaron distintas soluciones para adaptarse a la vida en un nuevo escenario. Algunos tuvieron suerte y consiguieron un empleo que les permitió vivir en casa propia o pagar un arriendo. Otros no tan afortunados, accedieron a empleos menos estables viéndose obligados a vivir de allegados en casa de parientes o amigos. Por último, otro grupo se dedicó a trabajar en alguna de las fincas que quedaban en Calama, intercambiando su conocimiento agrícola por un espacio donde alimentarse y pernoctar. ${ }^{5}$

Es importante enfatizar que no todos los migrantes tienen la misma suerte al tratar de insertarse en el nuevo espacio que los recibe. En el caso de Socaire, Imilan (2007) describe a aquellos que gozan de una residencia estable en Calama en el transcurso de los años. ${ }^{6}$ Son migrantes que han logrado vincularse en forma segura a alguna empresa minera,

irá en aumento debido al crecimiento poblacional y a los planes de mayor industrialización. Por tanto, la falta de agua en los oasis se tornará más severa en el futuro. En todos los oasis hay terrazas que hoy permanecen sin cultivar e indican que antiguamente había más tierras cultivables que en el presente" (Bähr 1985: 8; traducción de los autores).

5 Las distintas soluciones buscadas por los migrantes y que presentamos en este artículo, fueron obtenidas de testimonios recogidos en el campo en abril de 2007 y marzo de 2008 , en el marco de la elaboración de la tesis doctoral "One world, many ethics. The politics of mining and indigenous peoples in Atacama", en proceso de escritura.

6 El estudio de Imilan (2007) tiene como unidad de análisis la comunidad de Socaire en el Salar de Atacama. Sin embargo, muchos procesos de movilidad que describe para Socaire se pueden extrapolar al resto de las comunidades atacameñas de las cuencas de Atacama y del Loa. 
particularmente CODELCO, que les ha "permitido acceder a una completa red de servicios sociales y financieros. Obtener un contrato permanente en la empresa estatal cuprífera es considerada la forma más segura de ascenso social en Calama" (Imilan 2007: 115). También se refiere al grupo de socaireños que no ha podido incorporarse a CODELCO y ha tenido que buscar alternativas menos rentables y más inestables, como emplearse por temporadas en algunas de las numerosas empresas subcontratistas que trabajan para la gran minería. Otras alternativas de integración ha sido el trabajo independiente como choferes de taxis colectivos, en pequeños almacenes de barrio o talleres mecánicos; en suma, cualquier oportunidad que se presente.

En un estudio más reciente que compara los procesos de migración indígena entre comunidades aymara, atacameña y mapuche, Gundermann y González (2008) logran dar luces sobre los aspectos compartidos en estos procesos a nivel nacional y en diferentes etnias, señalando que:

"El paisaje indígena actual mantiene un anclaje menos intenso en las condiciones rurales de vida y trabajo, presenta una correlativa disminución de la dependencia de recursos agrarios, avanza la descomposición del perfil campesino de las economías indígenas y la redistribución espacial de sus contingentes es masiva" (Gundermann y González 2008: 107).

A esto lo denominan "poscomunalidad" y agregan que "a partir de su generalización, la movilidad espacial y residencial, la multiocupación y los multi-ingresos, la inestabilidad y precariedad de los empleos, así como la redefinición de la ruralidad y sus significaciones constituyen aspectos claves de caracterización" (Gundermann y González 2008: 107). En el caso particular de Likantatay, los procesos de integración regional de sus miembros han ocurrido mayoritariamente dentro del grupo que Imilan (2007) describe como aquellos migrantes que no han conseguido contratos estables en empresas mineras. ${ }^{7}$ Más bien, han tenido que conformarse con empleos precarios y con la generación de estrategias multi-ingresos en las que se incluyen la combinación de ingresos agrícolas, pecuarios, salarios por cuenta propia y pensiones del Estado. ${ }^{8}$

\footnotetext{
7 Solo un comunero en Likantatay goza de un contrato estable con la empresa minera CODELCO.

8 Un balance de las economías atacameñas lo realizan Gunder-
}

Es importante tener en cuenta que el éxodo de los pueblos del interior se produjo en una época en que ser indígena era considerado casi como una vergüenza debido a la fuerte discriminación racial y cultural que recibía quien se reconociera como tal, e inclusive quien lo pareciera, aun sin reconocerse indígena. Es solo a mediados de la década de los 90 que dicho panorama comienza a cambiar gracias a la promulgación en 1993 de la Ley Indígena 19253. Esta ley permitió que se instalara una nueva discusión en la escena política: el reconocimiento de la existencia de pueblos indígenas en el país, y el respeto a la diversidad cultural. A partir de ese momento histórico se produjo un giro radical en la concepción de lo indígena: pasó de ser un motivo de vergüenza a ser motivo de orgullo. Vergara y colaboradores (2006) señalan que la base de la actual política indigenista del Estado chileno fue el establecimiento de mutuo apoyo entre la Concertación de Partidos por la Democracia y los representantes del mundo indígena. El objetivo era derrocar políticamente al gobierno militar de Pinochet e instalar el proceso de transición a la democracia en Chile. La alianza entre el mundo indígena y la Concertación se vio materializada a través del llamado Acuerdo de Nueva Imperial a fines de 1989. Los acuerdos asumidos incluyeron la elaboración de una ley indígena que considerara la creación de una institución especialmente dedicada a velar por el cumplimiento de la Ley y los asuntos indígenas, la aprobación del convenio 169 de la Organización Internacional del Trabajo (OIT), y el reconocimiento constitucional de los pueblos indígenas. Estos tres compromisos inauguraron una nueva relación entre el Estado chileno y los pueblos originarios. Los funcionarios primero de la CEPI y después de la CONADI se convirtieron en los "mediadores" entre el mundo indígena y el no indígena.

mann y González (1995) al describir cómo, casi sin excepción, las familias atacameñas rurales tienen tres, cuatro o más fuentes de entrada de bienes y dinero. Los autores afirman que: "En ellas [las familias] suele estar siempre presente un componente de autoproducción para el autoconsumo, una suerte de recurso final al que acudir cuando los nunca muy seguros recursos provenientes del mercado o del Estado escasean" (1995: 102). Este diagnóstico de las economías campesinas atacameñas coincide perfectamente con la situación enfrentada por las familias de Likantatay en el presente.

9 Cabe destacar que, en principio, el mundo indígena vio estos cambios en la relación con el Estado con mucho entusiasmo. Sin embargo, la vigencia práctica de la Ley Indígena fue severamente cuestionada con el conflicto suscitado por la construcción de la Re- 
Dentro de este contexto, un grupo liderado por el entonces integrante del Directorio de la Comisión Especial de Pueblos Indígenas (CEPI), indígena migrante del pueblo de Ayquina, visualizó un proyecto revolucionario para la época: crear un espacio que replicara las condiciones de vida de los pueblos del interior, incluidos la agricultura y la ganadería, pero en la ciudad. Dicho espacio estaba pensado para trasladar a los ancianos originarios de los pueblos que se encontraran viviendo como allegados en casas de parientes, pero que no hubiesen abandonado la esperanza de poder volver a cultivar la tierra y criar animales. El sueño que tuvo en ese entonces el director de la CEPI se convirtió en lo que hoy es la comunidad indígena de Likantatay.

En la actualidad, Likantatay es una comunidad atacameña urbana ubicada en el sector poniente de la ciudad de Calama sobre un antiguo sector de vega de pastoreo. En 1991 un grupo inicial de 16 familias de atacameños inmigrantes de varios pueblos del interior (Ayquina, Caspana, Cupo, Toconce, Chiu Chiu, San Pedro de Atacama, Toconao, Socaire y Río Grande), presionados por las condiciones marginales en las cuáles vivían en la ciudad decidieron hacer una petición de tierra al Ministerio de Bienes Nacionales y se asentaron en el sector Cerro Negro de Calama, situado en las afueras de la ciudad. Se trataba de una tierra eriaza, sin servicios públicos, ni infraestructura habitacional. Bajo tales circunstancias, estas familias tuvieron que construir un espacio para sobrevivir.

Desde sus inicios, la gente de Likantatay declara que su principal objetivo comunitario es replicar, en la medida de lo posible, la comunidad tradicional atacameña en un espacio urbano. Tomando ese objetivo como base, los comuneros elaboraron un discurso y han venido ejecutando una serie de acciones que reflejan lo que para ellos constituye una identidad indígena legítima. Likantatay fue concebido

presa Ralco en el río Bío Bío (sur de Chile), en la segunda mitad de la década de los 90 . Al respecto, Vergara y colaboradores (2006: 354) cuentan: "La CONADI, dirigida sucesivamente por dos mapuche, consideró que los acuerdos de permutas de tierras entre las familias pehuenche afectadas y la empresa (ENDESA) violaban la Ley Indígena. Ante ello, el gobierno decidió intervenir la CONADI a fondo, solicitando la renuncia del Director Nacional, Domingo Namuncura, quebrando el consenso existente entre las organizaciones y el Estado, ya afectado con la renuncia obligada del anterior director, Mauricio Huenchulaf, y estableciendo a través de un acto de fuerza, su hegemonía sobre el Consejo de la CONADI." como un espacio para aquellos inmigrantes atacameños que añoraban el cultivo de la tierra, la crianza de animales y la práctica de ceremonias y fiestas rituales como el Carnaval, Todos los Santos y la "limpia de canales", entre otras, como alguna vez lo hicieron en sus pueblos de origen, pero que por vivir en una casa minúscula en la ciudad les era imposible hacerlo (Carrasco 2007). El siguiente testimonio refleja el sentimiento de la mayoría de los comuneros de Likantatay respecto a las condiciones mínimas necesarias para desarrollar su identidad indígena:

"En los estatutos oficiales de la comunidad decimos que nosotros como atacameños debemos tener agua y tierra. Esa es la creencia entre los indígenas, sin tierra y agua no somos nada. Necesitamos territorio para poder practicar nuestras costumbres y realizar nuestros rituales, todo lo que viene de nuestra cultura necesita un espacio para ser desarrollado y hacer nuestras actividades y agricultura y criar animales que es la forma en que vivíamos en nuestros pueblos de origen. Esta es la razón por la que demandamos títulos de tierra, y pienso que toda la gente que se instaló aquí tenía el mismo tipo de pensamiento porque no se sentían cómodos en la ciudad" (entrevista, diciembre de 2005).

En sus 18 años de existencia como comunidad, la gente de Likantatay ha logrado mejorar su situación económica mediante sus prácticas agropecuarias; ha podido conseguir instalar infraestructura básica que incluye agua potable y electricidad para todos los predios, una sede de reuniones y una iglesia; y ha obtenido, después de salvar muchos obstáculos, títulos de dominio sobre los terrenos y derechos de agua para irrigarlos. Para sus logros, los comuneros de Likantatay han tenido que valerse de múltiples instrumentos o "armas" que van desde la sencilla redacción y envío de cartas a un sinnúmero de entidades oficiales y no oficiales, hasta la ejecución de acciones más audaces como la toma del edificio de la Gobernación en la ciudad de Calama.

De acuerdo a los testimonios de miembros de la comunidad, cuando recién llegaron a lo que hoy es Likantatay no había nada, ni siquiera un árbol. Tuvieron que comenzar por preparar la tierra y pensar cómo iban a conseguir el agua para regar los campos.

"Comenzamos a mirar las aguas servidas que pasaban cerca, mirando eso y también observando a un grupo de vecinos del sector Cerro Negro, nosotros observamos cómo es que usaban aguas ser-

No $38 / 2009$

ESTUDiOs ATACAMEÑOS

Arqueología y Antropología Surandinas 
vidas, ese era el sistema de irrigación de ellos, y nosotros los imitamos. La cosa era, como puedo decírtelo, bueno básicamente robando agua, robar agua de otros" (entrevista, enero de 2005).

Un grupo de miembros de la comunidad se organizó, construyó canales, rompió la tubería del alcantarillado público y comenzó a regar la tierra con las aguas servidas. Para evitar ser sorprendidos por las autoridades locales, regaban durante la noche a través de un sistema de turnos que todos respetaban. Con dicha fuente ilegal de agua la gente de Likantatay irrigó sus cultivos durante 10 años (1991-2001). En 2001 tuvieron que dejar de usar este sistema de riego ya que la Compañía de Aguas Antofagasta (ex ESSAN) inauguró la Planta de Tratamiento de Aguas Servidas de Calama, e instaló un sistema nuevo de tuberías de alcantarillado, esta vez con tubos más gruesos y resistentes y a mayor profundidad bajo tierra. Se volvió imposible continuar "robando" agua de dicha fuente. Incluso si hubieran logrado acceder a la tubería y romperla nuevamente, la Compañía de Aguas había instalado un sofisticado sistema para determinar con exactitud la cantidad de lt/seg que la planta de tratamiento estaba procesando. Cualquier anomalía en el flujo normal de agua producto de alguna perforación intencional de la tubería sería detectada de manera inmediata y los inculpados puestos a disposición de las autoridades. Cuando esto sucedió, los comuneros se enfrentaron a lo que hasta el momento consideran la crisis más grave a lo largo de su historia. Como respuesta a dicha crisis, la comunidad primero solicitó y después exigió al Director Nacional de la Corporación Nacional de Desarrollo Indígena del momento destinar recursos del Fondo de Tierras y Aguas para solucionar el problema que la aquejaba y que de paso amenazaba su futuro en el lugar. Estas peticiones no resultaron fáciles. ${ }^{10}$

${ }^{10}$ Las acciones de la comunidad de Likantatay implicaron una fuerte relación con la CONADI. Debe reconocerse que en los inicios de Likantatay, la CONADI prestó un fuerte apoyo a sus comuneros y otorgó el respaldo político-institucional que entregaría la legitimidad requerida por el proyecto de la comunidad. Sin embargo, los dirigentes indígenas que trabajan en la CONADI muchas veces se vuelven agentes del Estado y del sistema político chileno, con lo cual dejan de jugar el rol de intermediarios efectivos del mundo indígena. Es por ello que una causa como la de Likantatay, que en un principio recibió fuerte respaldo institucional de parte de la CONADI, hoy en día ya no lo recibe. Esta tensión que viven los funcionarios indígenas en la CONADI (representar la causa indígena vs. avanzar en los intereses del Estado chileno) genera mucha animadversión entre ciertos sectores indígenas. Esta crítica se ve refle-
Los comuneros de Likantatay tuvieron que realizar continuas gestiones para que finalmente se asignara la suma de 540 millones de pesos para la compra de derechos de agua del río Loa para la comunidad. Su último logro importante como comunidad, luego de mucho esfuerzo, sacrificio y dedicación, fue el término de la construcción, en marzo de 2007, de un canal de regadío de $3 \mathrm{~km}$ de largo, para el cual tuvieron que gestionar permisos de paso por varias propiedades del sector, para poder traer el agua desde la finca Tomic hasta sus parcelas. En la actualidad los comuneros riegan sus campos de manera legal gracias a sus derechos de agua del río Loa. Sin embargo, recuerdan con nostalgia la época en que regaban con aguas servidas ya que la productividad de las cosechas era superior hasta en $50 \%$ a la actual, puesto que esas aguas, en sus palabras, "venían con el abono incorporado".

Considerando lo anterior, cabe preguntarse: ¿En quéconsistía este estilo de vida campesino en los pueblos del interior que los comuneros de Likantatay se han empeñado con tanto ahínco en reconstruir? Esta pregunta resulta clave porque ese "estilo de vida" es una referencia fundamental para entender las prácticas nostálgicas ${ }^{11}$ encontradas en la elaboración de identidades indígenas vividas en contextos urbanos como Likantatay. En sentido amplio y según sus protagonistas, se trataba de una forma de vida comunitaria donde las tareas familiares eran combinadas con trabajos colectivos (minga) propios de las actividades agrícolas y de los circuitos pastoriles. En la medida que gran parte de la producción agrícola sobrepasaba las necesidades de subsistencia de la población local, esta era vendida en los campamentos mineros de la región. También existía la costumbre de transportar

jada en un sobrenombre de circulación frecuente que se refiere a la CONADI con el nombre de "CON NADIE", dando a entender que los indígenas no cuentan con suficiente apoyo en dicha institución.

${ }^{11}$ La noción de prácticas nostálgicas es introducida por Battaglia (1995: 116), quien señala que la construcción del Yo es un proyecto crónicamente inestable que en forma situacional puede ser llevado a algún estado de orden, acomodado a algún objetivo, en forma consciente o de otra manera, en prácticas sociales indeterminadas. Dicho proyecto de construcción del Yo lo sitúa, en el caso particular que analiza sobre trobriandeses urbanos, en lo que define como "prácticas nostálgicas". A grandes rasgos, son todas aquellas prácticas que hacen los indígenas urbanos a través de un proceso selectivo de la "tradición" que consideran representa una identidad indígena "legítima". Esto quiere decir, una identidad indígena respetada por "nosotros" y reconocida por los "otros". 
productos de un pueblo a otro para realizar intercambios, valiéndose de animales de carga como llamas y burros.

En la medida que cada pueblo producía diferentes cosechas y otros bienes, tanto pastores como agricultores viajaban hasta el mercado local de San Pedro de Atacama, donde se realizaban los intercambios. El siguiente testimonio que recordó y relató una mujer comunera de Likantatay ilustra lo anterior:

"En el pueblo no usábamos eso de tener una revista, un diario, bebidas, té, café, azúcar, o nada. Allá, todo era natural, por ejemplo, la chicha de maíz hecha por mi abuela, esa era nuestra bebida [...] Mi abuelita viajaba hacia San Pedro de Atacama con sus burros, ella se perdía durante 15, 20 días y a veces hasta un mes. Ella tejía artesanías, tejía frazadas, calcetines, gorros de lana y mi abuelito tejía los accesorios de los hombres. Ambos viajaban con esos productos a San Pedro de Atacama y de allá traían maíz, choclo, frutas como la pera, higos y todas esas cosas. Mi abuela mantenía esas cosas guardadas para proveer a la familia durante el año. Todos los productos cultivados en el pueblo también eran para el año. Todo esto era hecho mediante intercambio, trueque, no había dinero" (entrevista, enero de 2005).

El estilo de vida campesino no solamente se caracteriza por un cierto tipo de economía, también está lleno de elementos a los cuales Núñez (1991: 233) llama el "espíritu atacameño" o "espíritu andino". Esos elementos son el conjunto de prácticas a las que los atacameños se refieren con el nombre de "costumbres". Likantatay señala como marcadores claves de su identidad indígena "legítima", la práctica de pagos a la tierra, la celebración del Carnaval, de Todos los Santos, el trabajo comunitario, el cultivo de la tierra y la crianza de animales. La vida en los pueblos del interior, dicen, estaba marcada por la práctica sistemática de estas costumbres.

Esta breve historia del origen, formación y luchas que ha enfrentado la comunidad de Likantatay, servirá para comprender mejor todo lo que está en juego para ellos como comunidad, tanto en términos materiales como inmateriales, si CODELCO llegara a concretar sus insinuaciones de un posible traslado a "futuro". Ello ocurriría de encontrarse cobre de alta ley bajo el suelo de estos comuneros que convirtieron una vega salada en uno de los pocos sectores agropecuarios que van quedando en los alrededores de Calama.

\section{* ¿Oportunidad o amenaza ante el TRASLADO DE LIKANTATAY?}

En mayo de 2007 la empresa minera CODELCO se acercó a la comunidad y convocó a una reunión en la que comunicó sus intenciones de explorar bajo Likantatay y determinar si el cobre encontrado era de alta ley como para que valiera la pena negociar, ya fuera un traslado o una indemnización con la comunidad. En dicha reunión, CODELCO se mantuvo en una posición altamente ambigua, en la que no concretó ninguna propuesta u oferta a la comunidad y siempre habló de "quizás, y tal vez en el futuro". Presionados por comuneros en la reunión, los representantes de CODELCO señalaron que ese "futuro" no sucedería antes de 2017.

Cabe preguntarse por qué si CODELCO manifiesta intenciones ambiguas ante la comunidad, se toma la molestia de presentarse e iniciar un proceso de comunicación con Likantatay. Para entender dicho acercamiento hay que señalar que el paradigma de relación de la minería y las comunidades tuvo un giro a nivel mundial, y por tanto a nivel nacional, a inicios de la década de los 90 y durante lo que lleva transcurrido del siglo XXI. Dicho paradigma giró desde ignorar a las comunidades aledañas a los yacimientos mineros hacia una toma de conciencia de los efectos que la minería podía tener y tiene sobre ellas. Un primer evento histórico que señaló el inicio de este cambio fue la conferencia internacional conocida como Earth Summit sostenida en Río de Janeiro en 1992. Dicha conferencia marcó un punto de referencia importante en las agendas ambientales en el mundo entero, vinculando de manera oficial los pueblos indígenas y el medioambiente al instalar el estereotipo que los indígenas por "naturaleza" tenían una relación armónica con el medioambiente digna de ser imitada por el mundo occidental. No es azaroso que en Chile en el año 1993 se promulgara la Ley Indígena 19253 y en el año 1994 se promulgara la Ley de Bases del Medioambiente 19300. Más que la primera, es la segunda la que comienza a generar un proceso de presión-reflexión al interior de empresas mineras como CODELCO, ya que por primera vez se ven obligadas a realizar estudios de impacto ambiental (EIA) para conseguir la aprobación de sus proyectos. Estos estudios, por Ley, incluyen la participación ciudadana. Es este factor, con todas sus limitaciones, el que obliga a las corporaciones a establecer un grado de

$\mathrm{N}^{\circ} 38 / 2009$

ESTUDiOs ATACAMEÑOS

Arqueología y Antropología Surandinas 
comunicación -aunque sea puntual- con las comunidades afectadas por sus proyectos. CODELCO no se mantiene marginada de las discusiones sobre producción minera y sustentabilidad, de manera que en 1998 participa en una importante reunión sostenida en Londres entre altos ejecutivos de varias de las empresas mineras más grandes a nivel mundial, entre las que se contaron Placer Dome, Río Tinto, Newmont, WMC, BHP Billiton, Noranda, Phelps Dodge, Angloamerican y CODELCO. De esa reunión resultó la propuesta de la Iniciativa Minera Global (Global Mining Initiative) que reunió a estas grandes empresas transnacionales en su búsqueda por definir el papel que juega la industria extractiva en el desarrollo sostenible y los desafíos que deben enfrentar en lo social, ambiental y económico. La iniciativa se funda en una especie de mea culpa que hicieron las empresas en su reconocimiento acerca de la forma no adecuada en que han operado históricamente. En el contexto de su participación como miembro de la Iniciativa Minera Global, CODELCO da a conocer su política medioambiental en el año 2000. Un año después, tomando en consideración que el medioambiente incluye grupos humanos, dicha empresa crea su política de relaciones con la comunidad. Es dentro del marco de estas políticas y en su afán de desarrollar una imagen corporativa positiva de relación con la comunidad que hoy día CODELCO se acerca a comunidades como Likantatay.

Muchos de los comuneros de Likantatay se encuentran tristes ante los rumores de un posible traslado forzoso si CODELCO confirma la existencia de cobre de alta ley bajo sus pies. Es un sentimiento común el que comparten al reflexionar que: "primero nos tuvimos que ir de nuestros pueblos de origen porque nos quitaron nuestras aguas, y ahora, nos quieren echar de Likantatay". Como dijimos en el apartado sobre los orígenes y formación de Likantatay, este asentamiento urbano representa aproximadamente 17 años de lucha por conseguir agua potable, agua para regadío, electricidad, títulos de dominio, preparación de terrenos para cultivo y construcción de viviendas, entre otros. Sumado a estos logros materiales, Likantatay representa la oportunidad de ser "alguien" para muchos de sus comuneros. Likantatay es el sustento material de su identidad, y por tanto, de su dignidad como personas. Muchos de los comuneros se niegan a aceptar tirar por la borda todo su trabajo y sacrificio por hacer surgir la comunidad de Likantatay. Sin embargo, en el fondo, saben que el cobre es "el sueldo de Chile" y que, de encontrarse riquezas bajo sus pies, ellos pueden ser los dueños de las tierras por Ley Indígena pero saben que los recursos del subsuelo no les pertenecen. Ante un proyecto minero que "beneficie" a mayor cantidad de gente, piensan que el Estado chileno no va a intervenir en favor de 36 familias atacameñas.

Cuando una comunidad se ve enfrentada, en este caso, a una oferta ambigua de reubicación, comienzan a generarse sentimientos encontrados entre sus miembros ya que la decisión de aceptar o rechazar ofertas externas depende en gran medida de las circunstancias de vida de cada una de las familias que conforman la comunidad. Por ejemplo, no es lo mismo aceptar un traslado para una familia que tiene un ingreso estable fuera de la agricultura, que para una familia que su sustento principal viene de su predio y no sabe o no puede hacer otra cosa para ganarse la vida. En Likantatay estas diferencias internas están presentes entre las familias, y es por ello que para unos la oferta de CODELCO representa una gran oportunidad y para otros la peor amenaza que han enfrentado después de los problemas que tuvieron cuando no pudieron continuar regando con aguas servidas.

Así, la decisión que enfrentan las familias de Likantatay está cargada de dilemas éticos con un significativo potencial de generar divisiones dentro de la comunidad. Por un lado, aceptar un traslado o algún otro tipo de compensación significa para algunos tirar por la borda gran parte de los valores comunitarios que dieron origen a Likantatay y que han estado presentes a lo largo de toda su historia, así como todo el trabajo físico y emocional invertido por cada una de las familias para lograr lo que hoy tienen. Sin embargo, por otro lado, aceptar los ofrecimientos de la empresa puede brindar a algunos comuneros la oportunidad de realizar cambios radicales de vida, como ofrecer educación superior a sus hijos, mejorar las condiciones de vivienda, o adquirir anhelados bienes de consumo. Esta última opción implicaría, necesariamente, hacer a un lado los objetivos colectivos que hoy día mantienen como comunidad y volcarse por completo a las necesidades y anhelos de la familia nuclear. ${ }^{12}$

\footnotetext{
${ }^{12}$ Lo esbozado no busca emitir juicios de valor a favor de una u otra opción, sencillamente busca abrir un espacio para discutir las contradicciones inherentes que enfrentan los seres humanos ante este tipo de encrucijadas.
} 
Independientemente de la postura de las diferentes familias ante la toma de la decisión de negociar u oponerse a CODELCO, hay una crítica compartida a la codicia que ha tenido históricamente esta empresa con el agua y el territorio indígena en la región. Por lo tanto, no es extraño que en su mayoría los comuneros de Likantatay desconfíen de las intenciones de la empresa. En palabras de una señora: "El ricachón siempre es más incorrecto que un pobre y eso es clarito, no hay duda de eso. Hay ricachones que tienen más plata, pero siempre quieren más. Ese es CODELCO" (entrevista, octubre de 2007).

\section{* Sistemas éticos y justificaciones ideológicas: ¿CÓMO HACER DEL DESARROLLO MiNERO ALGO JUSTO PARA LIKANTATAY?}

A lo largo de su trayectoria, el sistema neoliberal no se ha caracterizado precisamente por buscar hacer del desarrollo algo justo para la colectividad o sostenible en términos ambientales. Su preocupación ha sido más bien hacer que lo parezca.

A continuación se discutirán los conceptos fundamentales de la ética utilitarista y la ética deontológica. Estos conceptos pueden ser considerados útiles a la hora de debatir y comprender, por un lado, la construcción de discursos fundados en sistemas éticos que conducen a las masas a convencerse que el sistema económico vigente (neoliberal) es no solamente justo y necesario, sino también irreemplazable; y por otro, las contradicciones a las que se ven enfrentados los seres humanos cuando se les presentan propuestas que pueden cambiar no solo sus condiciones materiales, sino también la filosofía de vida bajo la cual han regido su existencia hasta el presente.

Como ya se mencionó, la ética utilitarista sostiene que si el total del bien es mayor que el total del mal, un acto es moralmente aceptable. Esto supone el principio de "mayor felicidad para el mayor número" y con base en ese principio se evaluarían los resultados y/o consecuencias de los actos (Rawls 1971; Lyons 1972; Pettit 1986). En contraste, la ética deontológica, cuyo mayor exponente es Kant, señala que el valor moral de una acción está dado por la motivación que hay detrás de la acción. Su teoría de la ética tiene cuatro dimensiones: a) razón/libertad; b) la dualidad de la condición humana; c) buena voluntad, y d) deber. Tener la habilidad de elegir el principio que guía nuestras acciones nos hace actores (Kant 2005).

En el encuentro que se generó entre la comunidad indígena y la empresa minera, se puede señalar que la corporación ha guiado sus argumentos con base en una ética de corte utilitarista. Esto se refleja en declaraciones de CODELCO como: "de encontrarse cobre rentable bajo Likantatay, no nos quedará más remedio que moverlos del lugar". Es decir, de concretarse la posibilidad de un negocio minero, esta minoría sería inevitablemente desplazada, bajo el argumento que los intereses de la empresa son los intereses de desarrollo de todos los chilenos; es decir, de la mayoría. En este sentido es que se podría hablar de un desplazamiento inducido por el "desarrollo" del país. En contraste, la comunidad indígena ha guiado sus planteamientos basados en una ética de corte deontológico. En esta priman las cuatro dimensiones señaladas con especial énfasis en los principios de razón/libertad que se ven reflejados en la fuerte defensa de la autonomía y la autodeterminación que ha mostrado la comunidad de Likantatay a lo largo de su historia. Lo anterior se expresa en una declaración frecuente entre muchos comuneros: "independientemente de la cantidad de dinero que me ofrezca la empresa por salirme de Likantatay, no estoy dispuesto a tirar por la borda toda la lucha que costó sacar adelante a la comunidad. Likantatay no tiene precio". Ahora bien, en un primer nivel de análisis se pueden identificar los sistemas éticos que rigen a unos y a otros. Sin embargo, en un segundo nivel de análisis se debe identificar cómo cada una de las partes involucradas logra (o intenta) hacer valer su versión ideológica de justificación ya sea del avance del capitalismo o de resistencia a éste.

Marx (1967) ya había hablado de un proceso de acumulación primitiva en el cuál los trabajadores son separados de los medios de producción. Siguiendo a Harvey (2004), este proceso de divorcio no es algo que pueda ser relegado a un pasado remoto, ni a un estado original del capitalismo. Se trata de un proceso constante de expropiación que sigue vigente al cual llama "acumulación por la vía del despojo". Este incluye una visión del trabajo como un bien de mercado, la privatización de tierras y derechos de propiedad, procesos de apropiación de recursos naturales, creación de sistemas de crédito, consumismo y endeudamiento.

$\mathrm{N}^{\circ} 38 / 2009$

ESTUDiOs ATACAMEÑOS

Arqueología y Antropología Surandinas 
Se podría agregar como hipótesis que todos estos procesos de despojo no se viven solamente en el ámbito de lo material, sino también en el de lo no material o ideológico. Si bien el despojo se produce en uno y otro ámbito, éste tiende a ser más evidente en el plano de lo material. Lo que buscaría el despojo ideológico es hacer del despojo material algo "aceptable". Resulta interesante que el despojo de lo ideológico sea un proceso sutil, relativamente extendido en el tiempo y casi imperceptible. Así, de manera paulatina, los valores indígenas tradicionales van siendo reemplazados por los de la modernidad. Este desplazamiento de valores sí puede ser percibido por los actores en el mediano y largo plazo, sobre todo por las generaciones más antiguas, pero en lo inmediato tiende a ser aceptado e inclusive anhelado sin mayores cuestionamientos, más aún cuando viene de la mano de una historia que cuenta que ser indio es ser menos que el resto de la sociedad. De esta manera, el despojo es total en todo sentido. No es sino a través de coyunturas como, por ejemplo, la promulgación de la Ley Indígena de 1993 que algunos vienen a darse cuenta de ello y recurren a las herramientas y derechos que dicha ley otorga a los pueblos indígenas y que les sirve para recuperar y defender lo que en el pasado no pudieron. Resulta paradójico pensar que justamente estos instrumentos surjan del mismo sistema que los ha oprimido y despojado sistemáticamente a lo largo de la historia.

Para desenmascarar estos procesos más sutiles de despojo resulta clave fijar la atención en el lenguaje e ideologías presentes en él, ya que son arenas privilegiadas para examinar las relaciones que se dan en contextos políticos y económicos en lo relativo a la formación de ideologías y en la disputa por la imposición de "verdades" legítimas. De esta manera, se pueden establecer con mayor claridad las conexiones que existen entre acciones comunicativas a nivel microcultural (p.e., lo que se dice en una reunión entre una empresa y una comunidad) con los contextos económicos y políticos de poder y desigualdad que se generan a nivel macro (p.e., el sistema económico y político imperante en Chile) (Woolard 1998).

Las corporaciones (y entre éstas, las mineras), están entre las instituciones sociales más poderosas, afectando con frecuencia las vidas de comunidades enteras. También las corporaciones se encuentran dentro de las empresas menos reguladas, capaces de trasladarse a voluntad a lugares donde haya mano de obra más barata,

contaminando el aire y el agua de regiones completas. Es por ello que no resulta extraño que se manifieste en la actualidad un interés creciente por parte de la sociedad civil en la ética de las corporaciones (Nash 2005) y exista una crisis de credibilidad en lo que hoy se publicita como su "responsabilidad social empresarial". Para atenuar esta falta de credibilidad, las corporaciones suelen realizar acciones que, al menos en teoría, favorecen a las comunidades y al medio ambiente de su área de influencia. Estas actividades comúnmente reciben el nombre de "greenwashing" (lavado verde) por parte de los activistas medioambientales, quienes consideran que dichas actividades son mínimas en términos de inversión económica y del impacto positivo real que generan, tanto en las comunidades como en el medio ambiente. ${ }^{13}$ Sin embargo, es importante resaltar que este tipo de gestiones van acompañadas de fuertes inversiones en términos de publicidad y propaganda. En los pueblos del interior de la cuenca del Loa abundan ejemplos de este tipo por parte de empresas como CODELCO: construcción de sedes sociales, reparación de iglesias, donación de materiales de construcción, contribuciones para la celebración de fiestas patronales y entrega de regalos navideños, entre otros.

El acercamiento que tuvo CODELCO a la comunidad de Likantatay en mayo de 2007 para informar sobre la posibilidad de iniciar exploraciones en un futuro no especificado es parte de lo que se podría denominar como una "nueva estrategia" por parte de la empresa, consistente en dar la impresión ante las comunidades de la región que la habitual prepotencia que ha caracterizado a CODELCO quedó en el pasado, y que ellos ahora sí "consultan" a las comunidades que podrían verse afectadas por sus acciones.

Resulta importante señalar que el acercamiento de la empresa ya ha generado lo que Molina denominó "preimpactos" para el caso de los pehuenche y la represa Ralco: “...estrés psicosocial de la población, fracturación de la unidad interna, desorganización de las comunidades, contradicciones y violencia en núcleos familiares

\footnotetext{
${ }^{13}$ Es evidente que este tipo de acciones de "beneficencia" por parte
de las mineras no reducen los índices de contaminación del aire,

3 Es evidente que este tipo de acciones de "beneficencia" por parte
de las mineras no reducen los índices de contaminación del aire, ni devuelven a los pueblos del interior los $1 \mathrm{t} / \mathrm{seg}$ de agua necesaria para la recuperación de su producción agrícola y ganadera.
} 
y propagación de un sentimiento de desesperanza de permanecer en sus tierras..." (Molina 1997: 19). Estos son justamente algunos de los síntomas que ya se evidencian en la comunidad ante la creciente incertidumbre de lo que será su futuro. CODELCO prometió regresar a Likantatay y mantener a la población informada sobre el avance del proceso; sin embargo, desde la visita de mayo de 2007 no se ha vuelto a tener noticias de la empresa.

Para ilustrar un poco estas "divisiones internas" (preimpactos) en la comunidad, resulta interesante realizar una síntesis de los resultados de entrevistas con aproximadamente $90 \%$ de las familias de Likantatay respecto a sus opiniones acerca del dilema que enfrentarían y qué exigirían a CODELCO de concretarse sus insinuaciones de traslado o indemnización.

De un total de 36 comuneros pertenecientes a Likantatay, cuatro no fueron entrevistados. Tres de ellos por dificultades para ubicarlos y concertar entrevistas y uno de ellos porque falleció antes de ser contactado para realizar una entrevista. De los 32 comuneros entrevistados, cinco están dispuestos a irse de Likantatay, y 27 no lo están. De los 32 comuneros entrevistados, 19 no tienen trabajo o ingresos fuera de la agricultura (esto no incluye ingresos por concepto de pensiones o venta de artesanías ya que son muy bajos). En cambio, 13 comuneros sí tienen trabajo o ingresos fuera de la agricultura (esto incluye arriendo de casas, terrenos, o trabajo asalariado o independiente). Se agrega este dato laboral ya que como mencionamos, puede ayudar a entender porqué una familia puede estar o no dispuesta a negociar con CODELCO, ya que su decisión de dejar Likantatay o pelear por ella también pasa, entre otras cosas, por alternativas de ingreso para su familia.

De los 32 comuneros entrevistados, en caso de verse en la situación de abandonar forzosamente Likantatay, 14 prefieren seguir con la agricultura, 13 prefieren dejar la agricultura, tres no saben qué hacer, y dos volverían a su pueblo de origen.

Con el objetivo de ilustrar la variabilidad de opiniones existentes en la comunidad y tener una noción del potencial de división interna respecto al acercamiento de CODELCO, a continuación presentamos las opiniones de cuatro de los 32 entrevistados, para proporcionar una imagen de las complejidades que pueden presentarse a la hora de establecer negociaciones entre una empresa y una comunidad que, lejos de ser homogénea, presenta mucha variación interna:

1) "En caso de verme obligada/o a negociar, que el billete sea bueno, pero más que la plata me gustaría que CODELCO le diera trabajo al menos a un hijo de cada familia de Likantatay en la empresa. Pero, prefiero que CODELCO compre un terreno y nos traslade a todos juntos, eso sería lo ideal. Pensando en disponibilidad de terreno agrícola en Calama está el de Juana Tomic al lado de Chunchuri, son terrenos grandes, que CODELCO los compre y que nos construya la sede, la iglesia, todo así como lo tenemos en Likantatay. Esa es mi idea, pero sé que hay vecinos que prefieren el dinero y punto. Igual, si nos trasladan nunca va a ser igual a lo que tenemos ahora. Nosotros luchamos por el agua potable, por el agua de regadio, por lavar las meloas, se trabajó como bestias en la construcción de un canal y se sigue luchando hasta el día de hoy. Además CODELCO no nos respeta, ve a los indígenas y agricultores como seres inferiores. Los de CODELCO se creen superiores" (entrevista, octubre de 2007).

2) "CODELCO tiene que tener dos tipos de trato con nosotros: uno individual y uno comunitario y por más que le moleste eso a CODELCO, el comunitario tiene peso. Acá en la comunidad de Likantatay es como en todos lados, todos piensan diferente, pero eso no significa que por ello dejemos de ser comunidad. Hay un hecho de peso y es que el agua de regadío de Likantatay es de propiedad comunitaria y si un socio se desentiende de la comunidad y se va, su derecho queda por estatuto en la asociación, de manera que, si hay cinco comuneros que quieren quedarse esos cinco van a ser comunidad. Por ello CODELCO no saca nada con dividirnos o intentarlo. Con el solo hecho de venir a intentar entrevistar a dirigentes hacen que la gente desconfie de su propia gente y piense que quieren negociar aparte con la empresa, cuando los comuneros deberían desconfiar de CODELCO y no de sus vecinos. Pero eso es culpa de CODELCO" (entrevista, diciembre de 2007).

3) "Pienso que lo mejor es que CODELCO valore todo lo que tenemos (agricultura, animales, vivienda, etc.) y nos den el dinero y así nosotros empezamos una nueva vida en otro lugar. No me veo haciendo agricultura en otro lugar que no sea Likantatay, ya que empezar todo el trabajo que nos costó preparar la tierra y tener animales en Likantatay de cero sería muy duro en otra parte" (entrevista, septiembre de 2007).

No $38 / 2009$

Estudios ATACAMEÑOS

Arqueología y Antropología Surandinas 
4) "Que la empresa me de el dinero que vale mi terreno y mis cosas en Likantatay y ahí yo veo si lo invierto en algún negocio o en un terreno en mi pueblo de origen. Querían of recernos un traslado a los terrenos al lado del río, el de los Tomic. Bonitos terrenos, pero ¿y la contaminación? Quedaríamos al lado de la mina que quiere abrir CODELCO en el sector poniente de Calama. Nos envenenarían a los humanos, a nuestros animales y a nuestros cultivos. Y después cuando estuviéramos sufriendo las consecuencias de la contaminación, nos dirían: "pero si yo te pagué" (entrevista, septiembre de 2007).

Como se puede apreciar en solo cuatro opiniones de un total de 32 registradas, ya se siente la gran variabilidad de puntos de vista y lo complejo que podría ser una negociación en caso que la empresa concretara sus intenciones de negocio. Existe otro factor importante que marca las decisiones de las familias y es su grado de apego o distancia con lo que se describió como el "estilo de vida campesino" y las "costumbres". Existen muchas familias que no están dispuestas a dejar esa forma de vida. Sin embargo, también existen no pocas familias que se encandilan con la idea del "progreso" y, como se mencionó, en ese caso CODELCO sería la oportunidad para cambiar sus vidas. Dada la autonomía de decisión de cada familia, está claro que no se puede imponer la misma solución a todos. Si existe un grupo de 14 familias que quieren seguir como comunidad y continuar con sus objetivos originales de reconstruir la vida del pueblo del interior en un espacio urbano, la empresa debiera respetar la decisión de dichas familias por mucho que le complique la logística a la corporación.

Todo indicaría que en un país como Chile esta comunidad indígena, o al menos el grupo de familias que quiere continuar como comunidad, no tiene forma de defender sus intereses si CODELCO se pone como objetivo llevar a cabo el negocio. Sin embargo, el relato a continuación que cuenta un caso de intento de traslado obligado de una comunidad agrícola en Ecuador, donde CODELCO en un momento tuvo intenciones de hacer negocios, deja la esperanza de que los indígenas sí tienen formas de lucha y de avance de sus discursos ideológicos como estrategias de defensa de sus intereses, que pueden inclusive llegar a frenar un proyecto minero.

\section{* Se frena un proyecto minero: INTAG, UN CASO EN EL NORTE DE ECUADOR}

A finales de la década de los 9o, en la región de Intag (Cotacachi, provincia de Imbabura) en el norte de Ecuador, DECOIN, una organización no gubernamental local, con ayuda de grupos ecuatorianos e internacionales, derrotó a la Mitsubishi en sus planes de desarrollar un proyecto minero de explotación cuprífera en la región. La transnacional minera anglo-australiana Río Tinto ya había mostrado interés en el pasado por explotar el mineral en la zona, pero sus incursiones no fructificaron debido a la decidida oposición de grupos locales.

La idea del proyecto consistía en reubicar a 100 familias con el fin de despejar un área para el desarrollo de una mina a rajo abierto y traer a cientos de obreros de otras partes del país para extraer el mineral de la gran reserva de cobre. Esta es una zona caracterizada por un frágil ecosistema de bosques en donde se practica agricultura a pequeña escala por parte de una población predominantemente mestiza. A principios de la década de los 9o, Bishi Metals, una subsidiaria de la Mitsubishi, inició trabajos preliminares en Intag. Sin embargo, después de muchas infructuosas reuniones con autoridades gubernamentales para detener el proyecto, el 12 de mayo de 1997 una gran conglomeración de miembros de las comunidades que veían afectados sus intereses por las acciones por parte de Bishi Metals recurrió a tomar medidas y acciones directas. Casi todos los bienes de la compañía fueron inventariados y removidos del área (después fueron devueltos a la compañía), y los equipos restantes fueron incendiados sin causar daños a personas. El gobierno de Ecuador reaccionó mediante una demanda por terrorismo en contra de dos de los líderes comunitarios y un líder de DECOIN, pero el caso fue sobreseído por las cortes ecuatorianas un año más tarde. Casi al mismo tiempo, el gobierno ecuatoriano quiso insistir en el proyecto minero e hizo intentos para que CODELCO lo desarrollara. Dichos intentos también se vieron truncados cuando Acción Ecológica de Quito envió a la activista Ivonne Ramos a Santiago (Chile) a una demostración de protesta que tuvo el apoyo inmediato de medioambientalistas chilenos. La protesta coincidió intencionalmente con la visita a Chile del entonces presidente de Ecuador, Fabián Alarcón, y la activista prácticamente se hizo arrestar por la policía. Esta "mala" publicidad convenció a CODELCO para retirarse (Martínez-Alier 2001: 8).

$\mathrm{N}^{\circ} 38 / 2009$

ESTUdiOs ATACAMEÑOS

Arqueología y Antropología Surandinas 
El ejemplo de Ecuador muestra como el creciente posicionamiento del discurso ecológico a nivel mundial, así como la presión ejercida sobre las políticas neoliberales por parte de diferentes actores políticos y civiles (particularmente en lo referente a privatizaciones, inversión extranjera, tratados de libre comercio y orientación exportadora), ha dado pie al adelanto de políticas y prácticas medioambientales y sociales "positivas" por parte de la industria minera en casi todos los países del mundo. En este contexto, las mineras se han visto en la necesidad de invertir en mejoras tecnológicas con el fin de evitar el riesgo de contraer pasivos ambientales. Haciendo esto intentan cumplir con las regulaciones ambientales de los países en donde operan y se adaptan a las expectativas del mercado de exportación (normativas ISO). ${ }^{14}$ Compañías que se mantuvieron en manos del Estado, como es el caso de CODELCO, también tuvieron que adaptarse a estándares más altos de producción y medioambiente para seguir siendo competitivas en el mercado mundial. Las mejoras en las prácticas mineras en Chile ocurrieron en el contexto de la transición hacia gobiernos más democráticos posteriores al régimen militar de Pinochet. Sin embargo, la extracción de aguas en las áreas áridas del norte de Chile, donde se encuentra concentrada la mayoría de la actividad minera del país, es una preocupación considerable y sigue creando conflictos con otros usuarios tradicionales del agua, como agricultores y grupos indígenas. No es de extrañarse, y así lo conjeturan al-

${ }^{14}$ ISO (International Organization for Standardization) es una organización no gubernamental a cargo de la elaboración de estándares internacionales y opera en una red de 157 países, un miembro por país, con un secretariado central en Génova (Suiza) que coordina el sistema. Esta organización no gubernamental forma un puente entre el sector público y privado. Por un lado, sus miembros están enraizados únicamente en el sector privado y de la industria. ISO posibilita que se genere un consenso para crear soluciones que cubran los requerimientos del sector de negocios y a su vez cubran las necesidades de la sociedad más amplia. La normativa que interesa cumplir a las empresas mineras es la ISO 14001 relativa a regulaciones medioambientales. Cumpliendo dicha normativa las empresas mineras obtienen un sello verde para sus productos ofrecidos en el exterior, en el caso de CODELCO, principalmente el cobre. Dicho sello permite al comprador saber que está comprando un producto que cumple con la normativa medioambiental internacional vigente. Existen compradores que como forma de sanción no compran productos que no posean sello verde. También es una forma que tienen tanto los compradores como los vendedores de demostrar que son ciudadanos "conscientes" con el medioambiente. gunos comuneros de Likantatay, que debido al alto valor que tiene el agua en el desierto para la minería, más que el cobre bajo sus pies, lo que CODELCO quisiera son los $52 \mathrm{lt} / \mathrm{seg}$ de agua de los cuales son dueños. Sea esto lejano o cercano a los intereses invisibles de CODELCO, el punto que se quiere reforzar es que ejemplos como el de Ecuador recuerdan que lo que más temen hoy las empresas mineras como CODELCO, es que salga lastimada su imagen corporativa. En otras palabras, se podría argumentar que si una empresa minera toma medidas para tener y presentar una imagen corporativa positiva ante la sociedad civil nacional e internacional en lo que respecta a medioambiente y sociedad, tal vez las posibilidades de que alguna comunidad que considere afectados sus intereses particulares por el desarrollo de algún proyecto no tenga la fuerza y argumentos suficientes para detenerlo. Sin embargo, la estrategia que vienen aplicando las comunidades afectadas por proyectos mineros es lograr la movilización del discurso ideológico del medioambiente, aprovechar su estrecho vínculo, también ideológico, con los valores indígenas, y declarar ante la opinión pública que su caso constituye una abierta violación a los derechos humanos. Así, en el caso que Likantatay sea obligada a trasladarse, por lo menos se lograría una negociación más justa, no solo en el ámbito económico sino en el respeto de la dignidad humana. El caso ecuatoriano pone de manifiesto que en la actualidad se presentan con mayor frecuencia escenarios en que las comunidades indígenas han tenido y pueden tener un impacto significativo sobre las empresas mineras, y no ser solamente las víctimas pasivas de los impactos que su industria genera.

\section{* Neoliberalismo, medioambiente y RESPONSABILIDAD SOCIAL EMPRESARIAL}

El impacto ambiental generado por empresas mineras y otras que afectan el bienestar humano, está siendo visto cada vez más como una flagrante violación a los derechos humanos. El implacable avance de la industria minera y la notoriedad de sus efectos negativos han hecho que mucha gente alrededor del mundo comience a ver sus derechos básicos comprometidos. Esto porque se atenta contra sus formas de subsistencia, su cultura, e inclusive sus vidas (Martínez-Alier 2001: 21). Una dimensión importante de los conflictos medioambientales que afectan el planeta en 
la actualidad tiene que ver directamente con valores. Más allá de aquellos valores de orden económico, las decisiones sobre el uso que se dará al "capital natural" implican cuáles intereses y formas de vida serán salvaguardados y cuáles serán sacrificados o abandonados. Un lenguaje común para estas "valorizaciones" no está disponible para tales decisiones (Martínez-Alier 2001: 22).

El neoliberalismo puede ser definido en forma simple como una filosofía política o visión de mundo de libre mercado y menos Estado. El argumento principal que expresan quienes están a favor del neoliberalismo consiste en que el mercado es más eficiente en contraste con las ineficiencias y altos costos de las intervenciones estatales (Livermann y Vilas 2006:3). Como se verá a continuación, resulta complejo poner en la balanza cuales formas de vida serán salvaguardadas y cuales sacrificadas dentro de los términos de referencia valóricos otorgados por la filosofía neoliberal.

Dentro del marco de esa filosofía, uno de los problemas que enfrentará, no solamente Likantatay, sino toda comunidad que se enfrente a una negociación con empresas mineras, es el concepto de medioambiente que manejan las empresas. En general, se puede señalar que las mineras tienen un enfoque instrumental del medioambiente. Clark (2005) define este tipo de enfoque como aquel que concibe la naturaleza como aquello que rodea a los seres humanos, reduciéndola a un conjunto de recursos que deben ser utilizados sabiamente, esto es "racionalmente", para el beneficio de la humanidad. Este enfoque instrumental no permite a la empresa minera considerar una visión crítica del lugar que ocupan los seres humanos dentro de este todo más grande. En este orden de ideas, es evidente que para las empresas mineras existe un claro divorcio entre seres humanos y naturaleza. Considerar el medioambiente como una categoría objetiva separada de los seres humanos les permite reconocer con relativa facilidad las responsabilidades empresariales y éticas con respecto a los daños medioambientales que causan sus actividades. Sin embargo, no deja lugar para el reconocimiento de responsabilidades con respecto a los daños causados a las personas que ahí viven. Esta situación conduce a cuestionarse si las corporaciones debieran o no ser presionadas y/o sancionadas por los daños y perjuicios materiales y no materiales causados a las personas.
Es evidente que los límites hasta donde pretenden llegar las corporaciones mineras al asumir responsabilidades sociales empresariales depende en buena medida del monto del presupuesto que cada corporación esté dispuesta a destinar para este fin, pero sobre todo del conjunto de políticas, directrices, y normativas que se establezcan para relacionarse con las comunidades. Un funcionario no saca nada con tener la buena voluntad de mejorar las relaciones con la comunidad si no cuenta con el respaldo financiero e institucional para hacer su trabajo.

Otro problema que enfrentan las empresas a la hora de asumir responsabilidades sociales se origina en las causas que motivan la inversión en el mejoramiento de sus relaciones con la comunidad. Por ejemplo, uno de los argumentos utilizados con más frecuencia por parte de ejecutivos de las empresas para justificar las pocas acciones positivas hacia comunidades particulares, es que su negocio beneficia a todo el país o a mayorías bastamente más relevantes que un grupo de 36 familias indígenas, como Likantatay. Muchas veces argumentan que debido a que el negocio minero aporta una parte importante de los ingresos totales del país, se vuelve aceptable que ellos no aborden problemas de relación con la comunidad de manera competente. En otras palabras, sus "compensaciones" son su contribución a la riqueza del país. ${ }^{15}$

Partridge (2005) ilustra con una interesante historia las complejidades que surgen a la hora de definir los parámetros para la compensación de una comunidad. Cuando las causas del daño son oscuras lo que tiende a suceder es que aquellos que son identificados por la sociedad mayor como los responsables de los daños, se resisten a la hora de asumir responsabilidades de compensación:

"Hace 25 años atrás, decidí botar mis pipas y mi tabaco, y nunca más fumé.Me diagnosticaron cáncer a los pulmones. Los médicos luego me dicen que después de 30 años sin fumar, sería raro que mis antiguos hábitos de fumador sean los causantes del cáncer. Más bien, he sido víctima de la mala calidad del aire del sur de

15 Dichas opiniones han sido registradas en notas de campo, producto de comunicación personal con diversos funcionarios de mineras a lo largo de investigaciones alrededor de la relación minería-comunidades realizadas entre los años 2001 y 2007.

$\mathrm{N}^{\circ} 38 / 2009$

Estudios ATACAMEÑos

Arqueología y Antropología Surandinas 
California, en particular, los humos y gases de más de 20 millones de automóviles [...]. Si las cortes de justicia son mi remedio, entonces ca cuál de todos los dueños de automóvil debo demandar debido al daño a mi salud por contaminación del aire? ¿cuál molécula de cuál automóvil fue "la última gota" que mutó la célula fatal? Finalmente, ccómo puedo estar seguro, 'más allá de cualquier duda razonable', que mi pipa para fumar no fue la causante? Dado que estas preguntas no son posibles de responder, pareciera ser que no existe esperanza alguna que sea compensado" (Partridge 2005: 440; traducción de los autores).

Esta historia sirve como metáfora para entender porqué muchas compañías mineras adoptan una posición defensiva cuando se ven cuestionadas respecto a sus responsabilidades sociales empresariales para con la comunidad y el medioambiente. Simplemente señalan que no hay forma de estar seguros, "más allá de duda razonable", de quién o qué ha causado los daños al medioambiente y a la gente. En el caso de CODELCO esta posición defensiva se presenta con frecuencia. Se puede sospechar que este tipo de opinión se produce debido a la existencia de muchas corporaciones vecinas trabajando en la región de Antofagasta. La gran pregunta siempre termina siendo: icuál de todas las corporaciones mineras en el área tiene la mayor responsabilidad sobre los daños medioambientales? El temor que tienen las empresas es que sus esfuerzos hacia una mejoría de las relaciones empresa-comunidad sean identificados con las "buenas prácticas corporativas" de otras empresas; es decir, que "sus esfuerzos" se vean confundidos con las acciones de empresas vecinas. Este tipo de preocupaciones conduce a pensar que los esfuerzos de las empresas mineras para debatir temas medioambientales están en gran parte direccionados hacia la construcción de una imagen corporativa positiva respecto a su relación con la comunidad y medio ambiente (greenwash), más que a temas de fondo como sería el desarrollo de prácticas medioambientales y comunitarias positivas. En un reciente estudio sobre los impactos de la gran minería en las comunidades indígenas del norte de Chile, Yáñez y Molina (2008) identifican cómo las empresas mineras tienden en forma sistemática, a no hacerse cargo de sus impactos al medioambiente y a las comunidades. Los autores señalan respecto a las comunidades vinculadas a la cuenca del río Loa, especialmente destacando el caso de Quillagua:

"No exageramos al decir que la situación de las comunidades in- dígenas ribereñas es dramática. La falta de agua ha forzado a los habitantes a abandonar los ayllu ancestrales y a migrar hacia otras zonas. Hoy persisten como poblados solo los ayllu de Quillagua, Chiu Chiu y Lasana. Sin embargo, el ayllu de Quillagua estará en vías de rápida extinción si no se resuelve a la brevedad su precaria disponibilidad de agua. En Quillagua, tras la promulgación del Código de Aguas de 1981, los derechos ancestrales de agua fueron asignados a título individual a los comuneros, muchos de los cuales los vendieron después a empresas mineras. En estos momentos, solo $30 \%$ de los derechos de aprovechamiento tiene como titulares a miembros de la comunidad de origen indígena, pero la realidad es que no escurre agua con la cual hacer efectivos esos derechos, al tiempo que la localidad de Quillagua enfrenta una situación de privación total del recurso. En el presente, la comunidad se abastece de agua potable mediante camiones aljibes, que suministran tres horas de agua potable tres días a la semana, por un volumen total de $60000 \mathrm{lt}$. El agua de uso agrícola, que hasta hace poco más de 10 años regaba $400 \mathrm{ha}$, hoy alcanza apenas para 1.5 ha, y sufre daños por contaminación que datan de 1997, daños que las autoridades y las compañias mineras han negado sistemáticamente, sin que ninguna se haga cargo de ellos" (Yáñez y Molina 2008: 142).

En conversaciones con indígenas de la región, en varias ocasiones señalaron con impotencia que no contaban con los recursos para hacer estudios y "probar científicamente" los daños al medioambiente y a la gente que causa la minería. Bajo la lógica de la "prueba científica" las mineras sustentan sus posiciones defensivas a la hora de no hacerse cargo de casos como el que Yáñez y Molina describen.

El predominio de la metáfora de la ciencia en la mentalidad corporativa supone una desaprobación implícita y muchas veces explícita de las interpretaciones indígenas de la realidad (p.e., que el agua es la sangre de la tierra). Esta falta de consideración sería desde el punto de vista indígena $y$, dicho sea de paso, desde cualquier otro punto de vista, por parte de las corporaciones uno de los principales obstáculos para un mejoramiento de las relaciones entre minería y comunidades. Para superar en parte dicho obstáculo se requeriría una intervención en el mundo de las empresas. Por ejemplo, en talleres o capacitación en los cuales se exponga a los ejecutivos y funcionarios mineros la existencia de otras perspectivas para interpretar el mundo. Estamos pensando en perspectivas alternativas a la idea de que toda afirmación o demanda que se formule solo será legitimada si va acompañada de pruebas cien-

$\mathrm{N}^{\circ} 38 / 2009$

ESTUdios ATACAMEÑos

Arqueología y Antropología Surandinas 
tífico-técnicas. En otras palabras, no todo lo que se puede contar cuenta, y no todo lo que cuenta se puede contar.

\section{$*$ Conclusiones}

A pesar de la existencia de una política formal de relación con las comunidades indígenas, en CODELCO la contradicción en la premisa de que una empresa puede al mismo tiempo sostener sus fines lucrativos y mostrar responsabilidad social empresarial sigue vigente. Hawken (2005) apunta a la contradicción inherente que hay en la premisa de que puede existir una corporación al mismo tiempo con fines lucrativos y presencia de responsabilidad social: "Elaborar un discurso, que una compañía puede hacer del mundo un lugar mejor, puede crecer, y puede incrementar ganancias junto con abordar necesidades sociales y medioambientales, es como pedir pan y pedazo y eso es una fantasía que no puede convertirse en realidad..." (Hawken 2005: 420; traducción de los autores). Esto debido a que la empresa tiene un claro corte neoliberal y su prioridad es optimizar hasta donde la ley lo permita el negocio de la explotación del cobre. Aparentemente, para las directivas de CODELCO pareciera no existir una forma fácil de conciliar inversiones sustanciales en las áreas sociales y medioambientales y al mismo tiempo generar las ganancias esperadas. Sin embargo, se valen de todos los medios de comunicación disponibles en la actualidad para dar a conocer a las comunidades indígenas, al pueblo chileno, a la competencia, a gobiernos extranjeros, entre otros, los "tremendos esfuerzos" que hacen para contribuir con soluciones al deterioro ambiental y al mejoramiento de la calidad de vida de los habitantes de su área de influencia.

O'Connor (2005) argumenta que la mayoría de los proble- mas ecológicos y socioeconómicos no pueden ser resueltos solamente analizándolos a nivel local. Se hace necesario situar las respuestas locales en contextos regionales, nacionales e internacionales. En palabras de Bookchin: "El campo de batalla real sobre el cual el futuro ecológico del planeta será decidido es claramente un campo de batalla social" (2005: 462; traducción de los autores). La experiencia ha demostrado que los conflictos medioambientales y sociales no pueden ser resueltos solo basados en variables económicas. Resulta evidente que los debates y acciones a futuro tendrán que incorporar aspectos éticos y morales ineludibles a la hora de discutir distribución de la riqueza, la distribución de impactos por generar dichas riquezas, y discusiones relativas a la inequidad generada por el "desarrollo" minero en el norte de Chile.

De concretarse las intenciones de CODELCO de iniciar un proyecto minero bajo los terrenos de Likantatay, sería conveniente que la empresa se preocupara de los temas éticos profundos que involucran cambiarle la vida a un grupo de gente que ha dado una dura batalla para forjarse una particular manera de vivir, un futuro y la recuperación de su identidad y dignidad.

Agradecimientos A la comunidad de Likantatay en su conjunto por el apoyo brindado y la confianza entregada al compartir sus visiones acerca de la minería. Un especial agradecimiento a la dirigente Vinca Espinoza, mujer elocuente y en extremo brillante en su asesoría del lugar que ocupan los indígenas en el sistema neoliberal. También agradecemos el incondicional apoyo de Lila Colamar y su familia, durante el proceso de investigación y trabajo de campo. Por último, agradecemos los valiosos comentarios críticos de los evaluadores anónimos, que contribuyeron enormemente a mejorar la versión final del artículo.

\section{$*$ Referencias citadas}

BÄHR, J., 1985. Agriculture, copper mining and migration in the Andean cordillera of Northern Chile. Mountain Research and Development 5:279-290.

BATTAGLIA, D., 1995. Rhetoric of self-making. University of California Press, Berkeley.
BOOKCHIN, M., 2005. What is social ecology? En Environmental philosophy. From animal rights to radical ecology, M. Zimmerman y J. Baird Callicot (Eds.), pp. 462-478. Upper Saddle River, Nueva Jersey.

BOURGUIGNAT, M. y S. RAMÍREZ, 2006. Pascualama: Identidades y conflicto en la cordillera huascoaltina. Tesis de Grado de 
Antropología Social. Departamento de Antropología, Universidad Academia de Humanismo Cristiano, Santiago.

CARRASCO, A., 2007. Likantatay. Recreando el paisaje de los abuelos. En Etnografías mínimas, D. Quiróz y P. Toledo (Eds.), pp. 143152. Colección Etnografías del Siglo XXI, Santiago.

CLARK, J., 2005. Introduction. En Environmental philosophy. From animal rights to radical ecology, M. Zimmerman y J. Baird Callicot (Eds.), pp. 361-389. Upper Saddle River, Nueva Jersey.

GUNDERMANN, H. y H. GONZÁLEZ, 1995. Tierra, agua y sociedad atacameña, un escenario cambiante. En Agua, ocupación del espacio y economía campesina en la región atacameña, P. Pourrut y L. Núñez (Eds.), pp. 78-106. Universidad Católica del Norte e Institut Français de Recherche Scientifique pour le Developpement en Cooperation, Antofagasta.

2008. Pautas de integración regional, migración, movilidad y redes sociales en los pueblos indígenas de Chile. UNIVERSUM 23: 83-115.

HARVEY, D., 2004. The new imperialism. Oxford University Press, Nueva York.

HAWKEN, P., 2005. A declaration of sustainability. En Environmental philosophy. From animal rights to radical ecology, M. Zimmerman y J. Baird Callicot (Eds.), pp. 419-429. Upper Saddle River, Nueva Jersey.

IMILAN, W., 2007. Socaireños en movimiento. Atacameños y Calama. Estudios Atacameños 33: 105-123.

KANT, I., 2005. Groundwork for the metaphysics of morals. Broadview Press, Peterborough.

LIVERMANN, D. y S. VILAS, 2006. Neoliberalism and the environment in Latin America. Annual Review of Environmental Resources 31:327-363.

LYONS, D., 1972. Rawls vs. utilitarianism. The Journal of Philosophy 69:535-545.

MARTÍNEZ-ALIER, J., 2001. Environmental conflicts, environmental justice, and valuation. En Just sustainabilities: Development in an unequal world, J. Ageyman, R. Bullard y B. Evans (Eds.). Earthscan, Londres. En prensa.
MARX, K., 1967. Capital. International Publishers, Nueva York.

MOLINA, R., 1997. Proyecto Ralco: Un impacto irreversible sobre comunidades pehuenche. Ambiente y Desarrollo XIII (2):19-21.

NASH, J., 2005. Corporate ethics and the survival of communities. Anthropology of Work Review 2-3: 15-19.

NÚÑEZ, L., 1991. Cultura y conflicto en los oasis de San Pedro de Atacama. Editorial Universitaria, Santiago.

O'CONNOR, J., 2005. Socialism and ecology. En Environmental philosophy. From animal rights to radical ecology, M. Zimmerman y J. Baird Callicot (Eds.), pp. 450-461. Upper Saddle River, Nueva Jersey.

PARTRIDGE, E., 2005. With liberty for some: A liberal critique of libertarian environmental policy. En Environmental philosophy. From animal rights to radical ecology, M. Zimmerman y J. Baird Callicot (Eds.), pp. 430-449. Upper Saddle River, Nueva Jersey.

PETTIT, P., 1986. Slote on consequentialism. The Philosophical Quarterly 36:399-412.

RAWLS, J., 1971. A theory of justice. Belknapp Press of Harvard University, Cambridge.

SANHUEZA, C. y H. GUNDERMANN, 2007. Estado, expansión capitalista y sujetos sociales en Atacama (1879-1928). Estudios Atacameños 30: 113-136.

SCOTT, J., 1990. Domination and the arts of resistance. Yale University Press, New Haven y Londres.

VERGARA, J. I., H. GUNDERMANN y R. FOERSTER, 2006. Legalidad y legitimidad: Ley indígena, Estado chileno y pueblos originarios (1989-2004). Estudios Sociológicos 71:331-361.

WOOLARD, K., 1998. Introduction: Language ideology as a field of inquiry. En Language ideologies: Practice and theory, B. B. Schieffelin, K.A. Woolard y P.V. Kroskrity (Eds.), pp. 3-47. Oxford University Press, Nueva York.

YÁÑEZ, N.y R. MOLINA, 2008. La gran minería y los derechos indígenas en el norte de Chile. LOM Ediciones, Observatorio de los Derechos de los Pueblos Indígenas, IWGIA, Santiago. 